IJ§ER

ISSN: 2149-5939
International Journal of Social Sciences and Education Research

Online, http://dergipark.gov.tr/ijsser

Volume: 1(2), 2015

\title{
Digital diplomacy-perspectives and impact on traditional diplomatic practices-case study: Digitization Impact on Romanian and Belgian na- tional diplomatic systems
}

\author{
Mihai Ovidiu Cercel ${ }^{1} \quad$ Raluca Georgiana Saftescu²
}

Received Date: 01 / 02 / 2015

Accepted Date: 01 / 04 / 2015

\begin{abstract}
Internet emergence multiplied the number of voices involved in international policy-making, accelerated the spread of information and increased its sources, and offered a framework from real-time communication, so diplomats have to handle with a complex international agenda. To stay competitive, they have to assimilate digital tools in their daily practice, digital diplomacy defining changes in structures, resources requirements, organizational management and processes of MFAs. This is a central point of this paper that is focused on the impact of digital disruption on traditional diplomatic practices. Based on digital diplomacy perspectives the article argues that, even if traditional diplomatic customs remain at the heart of diplomatic activities, internet introduces a new dynamism in conducting diplomacy. A key change refers to embassies empowerment, their role inside diplomatic systems increasing while the centrality of MFA is challenged by the changing operating environment. The article emphasizes that some activities conducted today in headquarters will be assigned more and more to the embassies, ICT using optimizing the resources and the structure of the diplomatic network. The case study regarding digitization impact on Belgian and Romanian MFAs, showed that ICT transformed the manner of sharing information and of attracting foreign audiences having huge penetration potential, data being transmitted quickly to millions targeted people. In this context, diplomats' professionalization is an obvious and welcomed approach, each MFA having particular methods to develop digital competences. Therefore, the integration of digital tools in the diplomatic work and their optimal use represent the prerequisites for efficiency in the $21^{\text {st }}$ century.
\end{abstract}

Keywords: Diplomacy, Foreign policy, ICT, Digital diplomacy

\section{Introduction}

The emergence of internet shaped specific patterns to $21^{\text {st }}$ century diplomatic environment, the fast-moving societal change produced by digital disruption confronting diplomacy with the challenge to adapt in order to remain efficient in managing foreign policy. New information and communications instruments determined the need to revise the traditional one to one diplomatic communication style and to build an open and inclusive dialogue with foreign citizens. This does not mean to replace negotiations with Tweets or posts on Facebook, but to complement the classical methods of achieving foreign policy goals with new tools able to make diplomats real time actors in the present interconnected world. The most valuable aspect of social media is, alongside the possibility to reach a broader and targeted audience, the opportunity to increase mutual understanding between governments and citizens worldwide. Against this background, this article examines the forthcoming of diplomacy in the digital age, exploring the concept of digital diplomacy and the implications of digital tools on traditional diplomatic practices. Therefore, a central

\footnotetext{
${ }^{1}$ Lecturer, PhD National University of Political Studies and Public Administration, BUCHAREST/ROMANIA, mihai.cercel@dri.snspa.ro

2 PhDc., National University of Political Studies and Public Administration, BUCHAREST/ROMANIA, raluca.saftescu@gmail.com
} 
Cercel, M.O., Saftescu, R.G. (2015). Digital diplomacy-perspectives and impact on traditional diplomatic practices-case study: Digitization impact on Romanian and Belgian national diplomatic systems. International Journal of Social Sciences and Education Research, 1 (2), 318-328.

assumption of the paper is that digital diplomacy defines changes both in structures and processes of ministries of foreign affairs (MFAs). In addition, secondary objectives are to present perspectives on digital diplomacy and to investigate how social networks impacts diplomatic activities. Structurally, the article is divided in two main parts. The first offers a view on the implications of digital disruption on traditional diplomacy and inquiries into what digital diplomacy is. At this state of the work, digital diplomacy can be considered a new instrument of diplomacy, resulted from the integration of Internet and Communication Technologies (ICT) in conducting diplomatic activities (Assanovo, 2010 in Nweke, 2012), or in other words, the use of ICT to collect, analyze and disseminate diplomatic information (Holmes in Bjola and Holmes, 2015).

The second presents a case study illustrating the experience of Romanian and Belgian national diplomatic systems, documented in interviews, activity reports and through official data analysis. The findings will offer interesting insights on ministries-embassies relations, on how ICT technologies, especially social media, are integrated in the daily activity of diplomatic representatives and on appropriate digital skills needful for diplomats in meeting digital evolution. Above all, we consider that such work is beneficial for improving knowledge in the field, as digital diplomacy is still a new subject in the academic literature and for both practitioners and further scholars interested to deepen the research.

\section{Diplomacy: perspectives and impact on traditional diplomacy}

\subsection{Digital disruption effects on diplomacy}

Many of the traditional elements of diplomacy are valid today as a century ago. The dialogue with other countries and organizations and the process of negotiating and signing agreements are completed by the same diplomatic custom. Undoubtedly all these activities still play a paramount role on the international diplomatic scene, but what have changed fundamentally are public opinion and its access to information. Digital effects engendered a disruption in the way that international relations are conducted as they impact real-time communication, instant access to data, and management of large amount of data or cyber-attacks. Therefore, a legitimate response of diplomacy to these challenges is the transition to the digital age. Online communication infrastructure allows a higher connectivity between people, institutions and communities, digitization accelerating decision making process and stimulating governments to become live actors (Potter, 2002).

Both at national and international level, Internet offers a new framework to persuade, three elements being essential to influence foreign leaders' opinions: online presence, participation and connection (Westcott, 2008). Foreign actions, decisions and declarations are quickly analyzed at home and those at home are immediately reflected in international debates. Meantime, citizens that use ICT in their daily life develop new competences through which they involve themselves at international level, irrespective of issue (Potter, 2002). Therefore, Internet has the potential to weak the traditional national state seen as focal point of political loyalty because it allows communities to merge and to act beyond national borders (Westcott, 2008). Together, these elements convert the public opinion in a key stakeholder of diplomacy, theoreticians naming this phenomena 'diplomacy democratization', because technology allows an increasing number of people to involve in the governance process and to change it frequently (Grant in Westcott, 2008). As the international agenda has been extended beyond traditional issues such as cooperation, trade and security, civil society has become the main element to project soft power successfully. Moreover, 
Cercel, M.O., Saftescu, R.G. (2015). Digital diplomacy-perspectives and impact on traditional diplomatic practices-case study: Digitization impact on Romanian and Belgian national diplomatic systems. International Journal of Social Sciences and Education Research, 1 (2), 318-328.

strong collaboration with civil society became a significant part of diplomatic functions and new technologies transformed non-governmental organizations in sources of information and in standards to measure the internal support of national policies (Potter, 2008).

All these show that internet brings a new dynamism in international relations. Thus, diplomacy, the main element to manage the interstate relations, is also involved in this new trend. The implications of internet are reflected in domains such as time and space, ideas, information, networks, institutional changes or service delivery.

Spreading ideas, as key part of soft power, is realized through online platforms, like websites, blogs or social networks. These ideas can take various forms, most frequently they being general suggestions of desired results (e.g. solutions to surpass a financial crisis), shaping international agenda (e.g. including priorities or changing themes), disseminating ideas or persuading the negotiation partners about a certain position or even manipulating them or the public opinion by imposing a particular view about an event, or a structural or legal fact (e.g. reforming an international organization) Thus, once it became essential to influence international public opinion, not only foreign diplomats and government officials, being present on virtual networks and sending targeted messages became also compulsory. On a large scale, both international organizations and foreign ministries have created websites and social media accounts to reach a broader public. To control and manage the spread of ideas in online, foreign policy representatives have to be familiar with these tools and to find ways to engage in discussions and debates, using well orientated, intelligent and imaginative strategies to assure that information is valid and reliable. As the virtual public is a key in the policy making process, not only official sources, but also internet is an essential instrument to collect data.

Moreover, the cross-border effect of ICT modified the relation between distance and time. Issues and conflicts at distance are brought to global public attention, the focus being on rapidity, mass media geopolitics, and commercial preferences and cultural imperatives.

All these shaped the working manner of diplomatic services as the organizational structure of the ministries of foreign affairs was changed, the daily work was optimized through digital communication tools, the correspondence became easier and the consular services started to be offered online (Westcott, 2008; Barston, 2014). The changes produces by rapidly evolving ICT do not mean the replacement of traditional instruments for managing foreign policy but their supplementation with new instruments that allow better interconnectivity. As new digital platforms offered the possibility to create interactive web content, to collaborate and to exchange ideas (Breakendridge, 2012), governments became aware that social media represents a potential way to manage international relations. Therefore, ignoring social networks that allow to send targeted messages and to foster mutual understanding between official and citizens around the world and considering them a passing trend can thwart the achievement of diplomatic objectives. The members of diplomatic corps have, thus, to understand deeply the specificities of each social platform used daily by citizens to inform, to build new relations and to interact (Deruda, 2014).

\subsection{Perspectives on digital diplomacy}

The relation between diplomacy and internet is presented in the academic literature as digital diplomacy (Bjola in Bjola and Holmes, 2015), e-diplomacy (Hocking et all, 2012), cyber-diplo- 
Cercel, M.O., Saftescu, R.G. (2015). Digital diplomacy-perspectives and impact on traditional diplomatic practices-case study: Digitization impact on Romanian and Belgian national diplomatic systems. International Journal of Social Sciences and Education Research, 1 (2), 318-328.

macy (Barston, 2014) or diplomacy 2.0 (Harris, 2013). Scholars present digital diplomacy as being a way to manage international politics through digital tools and virtual collaborations, having a paramount impact on decision making process, public diplomacy and professional norms.

The apparition of web technologies 2.0, especially of social networks like Facebook and Twitter, stimulates diplomats to pay more attention when they transmit information to targeted foreign public segments. They are involved in policies promotion process because they interact with foreign authorities and foreign public opinion. Therefore, digital diplomacy is a form of public diplomacy. From this perspective, the public diplomacy aims to produce, disseminate and keep knowledge able to support the fulfilling of foreign policy objectives. New technologies, especially social media, have transformed information exchange process and the ways to attract foreign audiences as only few online platforms have the potential to assure a resilient informational penetration and data can be rapidly transmitted towards wider audiences (Holmes Bjola and Holmes, 2015). All these highlight that using ICT in diplomacy has three functions: firstly, to foster communication between states; secondly, to present the national foreign policy objectives inside and outside the country (Nweke, 2012, 22) and thirdly, to improve and to remodel the communication process between foreign affairs ministries and embassies and between the diplomatic missions of a state (Hocking and Melissen, 2015).

In the diplomatic arena, digital diplomacy covers various perspectives, as following (Hocking and Melissen, 2015):

Changing foreign policy environment: the internet emergence accelerated information diffusion due to high transmission speed and very low costs. Currently, information dispersion through ICT technologies has a considerable impact on governance and power diffusion, producing changes on former and speeding the latter. Thus, through internet, information spreads quickly, at low cost and with a small number of intermediaries, becoming a resource of power because access barriers are reduced or even eradicated. In these circumstances, private individuals and organizations, NGOs or corporations, play an increasingly role in world politics to the detriment of governments (Nye, 2012). In other words, global mass communication and ICT development represent challenges to the traditional way of managing international relations, dispersing authority in multiple directions, increasing global civil society activism and leading to an expansion of global trade and finance. Online telecommunications have enabled greater connectivity between individuals, institutions and communities, digitization leading to acceleration of decision-making process and requiring governments to become real time actors, their capacity to mobilize digital assets being a significant factor of digital environment (Potter, 2002; Hocking and Melissen, 2015).

Knowledge and resources management: this second perspective refers to the management and analysis of growing information flows. As sources of power have become more diffuse and decentralized and public finances have either remained constant or declined, governments tries to adapt, internet being one suitable solution. In this case appears a paradox, since quickness and ease of online communication also enable faster rumors spread, controlling them becoming a challenge for diplomats. As in an interconnected world more communication does not guarantee better communication, but on the contrary most often it multiplies the possibility of misunderstanding and misinterpretation, there is a need to create a tie between government information and cultural relations. Last but not least, this dimension highlights the use of digital technologies as tools to manage more 
Cercel, M.O., Saftescu, R.G. (2015). Digital diplomacy-perspectives and impact on traditional diplomatic practices-case study: Digitization impact on Romanian and Belgian national diplomatic systems. International Journal of Social Sciences and Education Research, 1 (2), 318-328.

efficiently the daily diplomatic activity, including communication, networks or hierarchical procedures (Copeland, 2013; Snow, 2009; Nye, 2012; Hocking and Melissen, 2015).

Cyber policy agendas: this perspective embodies various sub-dimensions, like cyber governance, Internet freedom, cyber warfare or cyber security. Taking into consideration that in today diplomacy the public is of paramount importance, governments find themselves in a dilemma regarding control and although it is important to generate soft power this is not always simple especially in the cyber era (Nye, 2012). Therefore, digital disruption and its impact on governments require taking advantage of resources such as infrastructure, networks, software and human ability to create, control and transmit electronic information, a phenomenon known in the literature as "cyber power". In a detailed definition, "cyber power is the ability to achieve the desired results by using interconnected electronic information resources" (Nye, 2012). In this context, cyber power appears to be dependent on information management, the effectiveness of this process depending on the model of managing large amount of information and on the degree of confidence in the available data and security systems (Westcott 2008). Consequently, internet governance has become a new topic in relations between states as it requires international regulation of cyber space environment by developing, in the first instance, globally dialogue and cooperation formats (Barston 2014).

E-governance and e-participation: this facet is associated with diplomatic services delivery and broader public participation in policy shaping. These imply especially building relations with foreign citizens, consular and crisis management and constructing and managing networks. Digital tools have a high potential to stimulate citizens to be actively involved in their society life, both home and abroad. In this context, social networks and digital communication instruments complete the traditional diplomatic mechanisms for managing international affairs, making them more effectively (Martin and Jagla, 2013; Hocking and Melissen, 2015).

\subsection{Digital tools impact on traditional diplomatic practices}

As previous paragraphs highlighted, digital diplomacy is a new instrument, being complementary to traditional diplomacy. Digital disruption offers several new tools for managing foreign affairs and, even if diplomacy remains conducted mainly by national governments as they hold the levers of law and power (Westcott, 2008), it impact both on diplomatic processes and on diplomatic structures (Hocking and Melissen, 2015).

\subsubsection{Implication on diplomatic processes}

Firstly, as regards the perspective of changing foreign policy environment, digital diplomacy weakens control over information flows, implies the necessity to develop online skills, requires strategies to obtain targeted policy results and accentuates the importance of leadership in information management. Secondly, related to knowledge and resource management, digital diplomacy impacts on data flow management and evokes new representation modes with potential to save resources, as for example laptop diplomacy. Moreover, if one analyzes cyber policy agenda perspective, there appear that digital diplomacy poses challenges on cyber spaces management in order to reduce the risk of cyber-attacks. Fourthly, e-governance and e-participation facet underlines that digital diplomacy is a new way to achieve foreign policy aims and to provide online public services such as trade and investment support, travel advice, passport and visa applications; also, it offers new ways to communicate and to build reputation or to manage crisis effectively 
Cercel, M.O., Saftescu, R.G. (2015). Digital diplomacy-perspectives and impact on traditional diplomatic practices-case study: Digitization impact on Romanian and Belgian national diplomatic systems. International Journal of Social Sciences and Education Research, 1 (2), 318-328.

and efficiently, but it emphasizes challenges related to data confidentially or diplomats readiness to change their current working way.

\subsubsection{Implication on diplomatic structures}

The impact of digital tools on diplomatic practice is felt in terms of organizational capacity of ministries of foreign affairs and diplomatic missions. Therefore, the institutional adaption, even if it is necessary, is a slow process, the subject being rather received with reluctance by the diplomats. However, digital diplomacy offers new working methods, so there is a need to integrate it in the organizational structures of MFAs. In other words, digital diplomacy is not only an answer to the online networks growth, but also a way through which ICT can be included in the daily diplomatic work, making it more efficient in this era of exponential changes (Hocking et all, 2012).

Moreover, to fulfill diplomatic functions in the digital age, MFAs should reform themselves, this process being two-folded: training and management and trust building. The first direction is based on the challenges faced by diplomats as they will work with networks of foreign audiences constantly growing. Therefore, they have to be prepared to answer quickly and strategically to new attitudes of other states and of international society. In a broader sense, a culture of using ICT in diplomatic practice will evolve, the professional background of actual and future diplomats including courses about how to use ICT and social media.

As concerns the second direction, trust building between governments and between them and foreign audiences, this is a key diplomatic exercise. Therefore, digital diplomacy has an utmost impact on growing or reducing political trust and it is an incentive for a more active involvement of citizens in the community life. A country image is influenced by online campaigns, through a combination of actions, words and images. Some communication methods are more suitable than others to transmit messages to targeted audiences and, in this context, the private sector involvement perceived as trustworthy can legitimate diplomatic actions (Martin and Jagla, 2013).

All in all, in the digital age, digitization of diplomatic work is the essence of keeping MFAs' competitiveness. Consequently, the number of ministries and diplomatic missions that provide online services is constantly growing. Additionally, digital communication technologies have the potential to involve not only foreign authorities, but also foreign public opinion in subjects related to foreign policy. As regards the changes that internet, especially social media, determined inside MFAs and diplomatic missions the need to keep their attractiveness accentuates the trend of diplomats professionalization, they being trained to be familiar with digital tools and to use them at their maxim potential. Also it determines organizational changes, as, for example, the formation of new departments specialized in online communication (Hocking and Melissen, 2015).

\section{Case Study: Digitization impact on Romanian and Belgian national diplomatic systems}

To examine the impact of digital disruption on diplomacy, the following section presents the implication of digital tools on Romanian and Belgian diplomatic systems. Both countries are members of the European Union, the former being still a novice, while the second is one of the founders and strong internationally orientated (Westcott, 2008). In this context, a comparative overview of the diplomatic structures will highlight how digital diplomacy is experienced in specific countries with different international profiles; thus the present case study will analyze the 
Cercel, M.O., Saftescu, R.G. (2015). Digital diplomacy-perspectives and impact on traditional diplomatic practices-case study: Digitization impact on Romanian and Belgian national diplomatic systems. International Journal of Social Sciences and Education Research, 1 (2), 318-328.

impact of digital tools both on structures and processes of MFAs to outline how foreign affairs are managed in Belgium and Romania in the digital age.

\subsection{Digitization impact on diplomatic structures}

Over last years, ICT became part of daily activity both of Romanian and Belgian MFAs. To respond to these technological changes, they adopt different strategies to accommodate their organizational structures in order to remain efficient. Therefore, inside the Romanian MFA, the Press Office disseminates public information and it manages communication in social media.

As regards Belgian MFA, it embodies in its organizational structure an ICT Department and a Press and Communication Department. The former has technical tasks, managing telecommunication infrastructure, while the latter stays in contact with public opinion. One special feature in Belgian MFA is that Press and Communication Department includes the Media and Communication Service which is responsible to manage ministry's social media accounts (Belgian MFA website, 2015).

Another dimension of diplomatic structure examined is the personnel. The interviewed representatives emphasized that understanding the importance of public communication by all diplomats is essential. Thus, inside the Romanian MFA there is an approach of informal learning, both for current and future diplomats because digital competences are considered to evolve as natural habit and it's necessary only to create the "reflex" to use them at work. The Belgian MFA has a different approach, focusing on staff training through specific workshops for all diplomats and special training sessions for those going to post.

Another sub-dimension here refers to Romanian and Belgian MFAs' websites that became part of their internal structure. Moreover, in order to use this tool at its maximum potential, the websites of Belgian embassies were renewed in 2013, being country-specific, rather than specifically for an embassy or consulate (Belgian MFA Activity Report 2013). As concerns the websites of Romanian diplomatic and consular missions and the online portal of Romanian MFA, they are connected to their social media accounts, each having its own content adapted to the specificities of its jurisdiction space. All these highlight that embassies' importance increase, they acting autonomously. Therefore, neither Romanian MFA nor Belgian MFA monopolize foreign affairs management anymore, they being contact points or coordinators of a broad network composed by other public authorities, NGOs or private stakeholders.

\subsection{Digitization impact on processes}

Both Romanian and Belgian MFAs' activities are a blend between online and offline, this mix referring to foreign policy environment, knowledge and resources management, cyber policy agendas and e-government and e-participation.

Firstly, as the previous chapter underlined, ICT affects the environment in which diplomats operate, this being more and more interconnected and interdependent. In this context, both Romanian and Belgian diplomatic systems are challenged because the immediate availability of information requests fast reactions and because domestic policies impact not only at national level, but also internationally. Moreover, as both countries are EU members, their internal and external policies follow the trend establish at EU level, being in accordance with the European agreements. Therefore, both Romanian and Belgian diplomats are internationally orientated and able to cope 
Cercel, M.O., Saftescu, R.G. (2015). Digital diplomacy-perspectives and impact on traditional diplomatic practices-case study: Digitization impact on Romanian and Belgian national diplomatic systems. International Journal of Social Sciences and Education Research, 1 (2), 318-328.

with a wide range of policy areas. Analyzing the activity reports of Belgian MFA during 20032013 (Belgian MFA website, 2015), one can notice that Belgian policies and activities are prioritized according to the developments on the international arena at a given moment. Similarly, Romanian diplomacy supports the fulfilling of European objectives and acts to manage foreign affairs in line with the values agreed internationally (Romanian MFA website, 2015).

Secondly, as respect knowledge management and resources, both Romanian and Belgian diplomatic systems are still involved in a process of technological modernization, improving their ICT infrastructure. Belgian MFA worked to incorporate digital tools in the daily operating practices, some example referring to the introduction in each Belgian consular mission of a high tech biometric system for visa, passports and electronic identity cards or to the equipment of all Belgian diplomatic missions with the adequate crisis communication assets. Moreover, in order to have a better overview of the management of Belgians world-wide, Belgian missions implement a crisis program that allows them to collect and store data about those living in their jurisdictional perimeter. In Romanian MFA, there is a similar approach, reflected, for example, during the Libyan conflict, when the Romanian consular offices in Tripoli created a database of Romanians in their area to permanently communicate with them by internet and telephone. Another key aspect linked with knowledge management is information that is contextualized in the diplomatic processes (Kurbalija, 2002). Both Romanian and Belgian diplomats interviewed highlighted they collect information from various sources, including social media networks, and they added that inside their ministries there is a strong concern for an efficient digital communication. Thirdly, as respect cyber policy agenda, both Belgian and Romanian MFAs support Internet openness and individual freedoms and they act according to Cybersecurity Strategy of the EU (Belgian MFA, Activity Report 2012-2013, Romanian MFA website). All these show that, as ICT emerging connected public policies to cyberspaces, both Romania and Belgium are aware of the importance to establish a common international cybersecurity policy and they put in place efforts to actively contribute to its developing and to act in relation to international agreements.

Fourthly, e-governance and e-participation perspective outline the tools used by the two ministries to communicate and to deliver services. Romanian MFA uses four social media platforms: Facebook, Twitter, Flickr and YouTube. The first three are also used by the Belgian MFA, this using also vimeo. Another sub-dimension here is related to data published on social networking platforms. Largely, these are the same as on the official website, but they are presented in a different manner, adapted to the specificities of each network. On Romanian MFA Facebook page the posts refer mainly to public diplomacy actions and on Twitter Page to minister's activities or to political events or policies with international impact. Belgian MFA uses social networks to 'amplify existing information on the website' (Belgian diplomat, interview, 2015). Its Facebook informational content is translated in three languages English, French and Dutch and it refers to ministry's activities, to key subjects on public agenda, to consular services or to travel tips and strengths of Belgium, while information transmitted on Twitter is 'short and fast, almost instantaneous' (Belgian diplomat, interview, 2015) and refers to the political work of the ministry and of the minister. Belgian MFA considers that Facebook addresses to general public, national or foreign, while Twitter is for journalists and professionals. Alternatively, Romanian MFA's Facebook page is addressed to Romanian public, the working language being Romanian, while Twitter account, primarily in English, is dedicated to foreign public. Last but not least, e-government and e-participation is strongly connected with the impact on publishing on social networks. In this 
Cercel, M.O., Saftescu, R.G. (2015). Digital diplomacy-perspectives and impact on traditional diplomatic practices-case study: Digitization impact on Romanian and Belgian national diplomatic systems. International Journal of Social Sciences and Education Research, 1 (2), 318-328.

regard, between the followers on Romanian MFA Facebook page (Ministry of Foreign Affairs, Romania, August 2015) and those on the Belgian one (Diplomatie.Belgium, August 2015) the difference is considerable: approximately 12000 compared to approximately 6000 . As concerns Twitter, international statistics show that the situation is reversed, Belgium ranking 67 out of 152 in terms of number of followers, while Romania 109 out of 152 (Agence France Press, E- Diplomacy Index). According to the diplomats interviewed, social networks contribute positively to their work because these allow them not only to reach various segments of the public, but also to evaluate their activity. Therefore, the Romanian diplomat said that social media is a complementary tool to official information sources and they have to take it into consideration, monitoring networks and providing appropriate answers to user's comments. Belgian representative argued in the same direction, stating that on social media, information spread faster, is more large, more accessible and easier to access by the general public who can easily obtain data and communicate from faraway geographical locations. All in all, the statements of the two diplomats highlight the positive contribution of digital diplomacy which is an adjuvant in their daily diplomatic work.

\section{Conclusions}

The present paper examined the extent to which digital diplomacy defines changes both in structures and processes of ministries of foreign affairs.

Firstly, as general conclusion it may be stated that digital disruption determines significant changes in the diplomatic systems of the $21^{\text {st }}$ century from two perspectives: the role of diplomatic missions and of ambassadors is increasing as poles of quasi-independent decision makers while the role of ministries of foreign affairs is weakening. The instant access to information, the need for immediate reactions, the reducing need for close coordination of diplomatic missions by the ministries, the increasing power and influence of ambassadors, the budgetary constraints that affects all foreign ministries and the quality and number of diplomats in ministry compared with those in posts abroad represents factors that will determine, in the near future, the translation of some activities from headquarter to diplomatic missions. This will lead to a decline in the coordination role of headquarters, their activities being limited to their own actions and those of the ministers, to analysis, planning and setting MFAs' strategic directions and to administrative and financial management.

Secondly, the study highlighted that new technologies, especially social media, revolutionized the manner of sharing information and of attracting foreign audiences in the sense that through few online platforms diplomats have the potential of a strong informational penetration, data being transmitted quickly to millions of people. The rather huge number of followers highlights that social media stimulates public involvement in foreign policy implementation. On the other hand, dealing with huge amount of data will require from the MFAs new capabilities in terms of personnel and technologies.

Thirdly, in terms of using new technologies in media, adaptation of foreign ministries was done differently. Thus, as concerns the organizational structure, digital/social media activity has been integrated into the work of each mission, being a tendency for assigning it to an already existing service: The Press Office in Romania and the Media and Communication Service in Belgium. 
Cercel, M.O., Saftescu, R.G. (2015). Digital diplomacy-perspectives and impact on traditional diplomatic practices-case study: Digitization impact on Romanian and Belgian national diplomatic systems. International Journal of Social Sciences and Education Research, 1 (2), 318-328.

Fourthly, as regards social media, the research revealed that the main social networks used by ministries are Facebook and Twitter. Differentiating between them is based on technical criteria, as for example the number of characters allowed or the target audience. In interviews, both diplomats spoke comparatively about Twitter and Facebook. The former is targeted to experts and professionals while the latter to general audience. However, certain traditionalism in not encouraging diplomats to express personal positions is found in both ministries. From experience, we found that this attitude is typical to continental European diplomacy that is more traditionalist than the British or American one.

Fifthly, with reference to the digital skills of diplomatic staff, the interviews identified a different approach of the two ministries. Thus, while Romanian MFA values digital skills acquired informally, in the context in which technologies have become part of everyday life, the Belgian MFA develops digital competences at institutional level through dedicated workshops and training sessions. This different view is kept in terms of digital skills of future diplomats. In this respect, the Romanian MFA cultivates a non-formal learning approach and it does not test digital competences in the admission exam, while the Belgian MFA evaluates them in the procedure for admission in the Diplomatic and Consular Corps. Additionally, social networks are adjuvants to the traditional manner to manage foreign affairs because they have a significant impact on strengthening or diminishing confidence and they are also incentives for an active involvement of citizens in the community life. Therefore, the integration of digital tools, both in the diplomatic structure and processes and their optimal use represent a precondition for diplomacy to stay efficient in the digital $21^{\text {st }}$ century.

Last but not least, the limits of our investigation are determined primarily by the preeminent qualitative character of the methods and approaches used in research. Information obtained through interviews was linked with literature and officials documents to avoid an image based only on official rhetoric. Another limit refers to interviews and it is related to the process of data collection - contacting diplomats was rather a difficult process and therefore there was conducted only one interview per country. In order to a deeply understanding of the subject, in further papers we envisage to use a more complex methodology, including interviews and focus groups with experts as well as surveys with national and foreign citizens to explore their perception on how digital tools are used by diplomats and to discover solutions to make full use of them in order to increase diplomatic actions efficiency.

\section{Acknowledgment}

We would like to bring our gratitude to the diplomats from the Romanian Ministry of Foreign Affairs, the Federal Public Service Foreign Affairs and the Romanian Embassy in Brussels, and to the researchers from the Egmont Royal Institute for International Relations participating to our research.

\section{References}

Barston, R. (2014). Modern Diplomacy, Fourth Edition, Routledge

Bjola, C, Holmes, M. (2015). Digital Diplomacy: Theory and Practice. Routledge, New York

Breakenridge, D. (2012). Social Media and Public Relations, Eight New Practices for the PR Professional. Pearson Education, New Jersey, 
Cercel, M.O., Saftescu, R.G. (2015). Digital diplomacy-perspectives and impact on traditional diplomatic practices-case study: Digitization impact on Romanian and Belgian national diplomatic systems. International Journal of Social Sciences and Education Research, 1 (2), 318-328.

Cooper, A., Heine, J., Thakur, R. (2013). The Oxford Handbook of Modern Diplomacy. Oxford University Press, Oxford

Deruda, A. (2014). The Digital Diplomacy Handbook. How to use social media to engage with global audiences

Harris, B. (2013). Diplomacy 2.0: the future of social media in nation branding. The Journal of Public Diplomacy, Vol. 4, Iss. 1, Art. 3

Hocking, B, Melissen, J. (2015). Diplomacy in the Digital Age. Clingendael Report. Netherlands Institute of International Relations- Clingendael

Hocking, B., Melissen, J, Riordan, S, Sharp, P. (2012). Futures for diplomacy Integrative Diplomacy in the 21st Century. Netherlands Institute of International Relations- Clingendael

Kurbalija, J. (2002), Knowledge management and diplomacy, DiploProjects, Mediterranea Academy of Diplomatic Studies, University of Malta

Martin, C, Jagla, L. (2013). Integrating Diplomacy and Social Media. A Report of the First Annual Aspen Institute Dialogue on Diplomacy and Technology, Aspen Institute, Washington, D.C.

Nweke, E. (2012). Diplomacy in Era of Digital Governance: Theory and Impact. Information and Knowledge Management, Vol 2, No.3

Nye Jr, J. (2012). Viitorul puterii, Polirom, Iași

Potter, E. (2002). Cyber-Diplomacy: Managing Foreign Policy in the Twenty-First Century. Montreal, QC, CAN: McGill-Queen's University Press

Westcott, N. (2008). Digital Diplomacy: The impact of the Internet on International Relations, Oxford Internet Institute, Research Report 16

*** Ministerul Afacerilor Externe (Romanian MFA website). (n.d.). Retrieved September 10, 2015, from http://www.mae.ro

*** Facebook page of Romanian MFA. (n.d). Retrieved September 10, 2015 from https://www.facebook.com/mae.romania?fref $=$ ts

*** Facebook page of Belgian MFA. (n.d). Retrieved September 10, 2015 fromhttps://www.facebook.com/DiplomatieBelgium-268916186486576/ timeline/

*** Federal Public Service Foreign Affairs (Belgian MFA website). (n.d.). Retrieved

September 10, 2015 from http://diplomatie.belgium.be/en

*** Federal Public Service Foreign Affairs, Annual reports. (2003-2013.). Retrieved

September 10, 2015, from http://diplomatie.belgium.be/en/ about_the_organisation/activity_report/ 